RESEARCH PAPER

\title{
Modulating effects of acepromazine on the reactive oxygen species production by stimulated equine neutrophils
}

\author{
Charlotte Sandersen*, Ange Mouithys-Mickalad†, Geoffroy de la Rebière*, Ginette Deby $\dagger$, Didier Serteyn* \\ \& Thierry Franck $\dagger$ \\ *Equine Clinic, Faculty of Veterinary Medicine, University of Liege, Liege, Belgium \\ $\dagger$ Centre of Oxygen Research and Development, University of Liege, Liege, Belgium
}

\section{Abstract}

Objective To investigate the effect of acepromazine (ACP) on reactive oxygen species (ROS) production by stimulated equine neutrophils.

Study design $E x$ vivo biochemical experiments.

Animals Isolated neutrophils from healthy untreated horses.

Methods Neutrophils were incubated with ACP at concentrations of $10^{-4}, 10^{-5}$ or $10^{-6} \mathrm{M}$ and then stimulated with phorbol-myristate-acetate (PMA) before measurement of lucigenin-enhanced chemiluminescence (CL). In a second experiment neutrophils were incubated in the presence of $\alpha$-keto- $\gamma$ methylthiobutyric acid (KMB) and treated with ACP at concentrations of $10^{-4}, 10^{-5}$ or $10^{-6} \mathrm{M}$. Subsequent PMA stimulation lead to neutrophilic ROS production and decomposition of KMB to ethylene, which is measured by gas chromatography. Electron paramagnetic resonance-spin trapping (EPR) analysis was performed with PMA-stimulated neutrophils in the presence of $\mathrm{ACP}\left(10^{-4}, 10^{-5}\right.$ or $\left.10^{-6} \mathrm{M}\right)$ directly added to the cell suspension. In the second experiment, the same concentrations of ACP were preincubated with neutrophils, then centrifuged to eliminate the excess of ACP and re-suspended in phosphate buffer before stimulation with PMA. In all experiments, the results of ACP-treated and ACPuntreated stimulated neutrophils were compared.
Results Overall, results obtained with lucigeninenhanced CL and KMB oxidation were in agreement with those seen in electron paramagnetic resonance spectroscopy. Acepromazine induced a dose-dependent inhibitory effect on neutrophilic ROS production. Electron paramagnetic resonance also showed, at high ACP concentration, the appearance of a cation radical derived from ACP. In contrast, electron paramagnetic resonance study performed with pre-incubated neutrophils showed an important dose-dependent inhibitory effect of ACP.

Conclusion The results indicate that ACP can neutralize $\mathrm{O}_{2}^{--}$or its by-products during the stimulation of neutrophils.

Clinical relevance These findings may have a therapeutic relevance when phenothiazines are used in horses suffering from inflammatory diseases in which neutrophil activation and ROS production are implicated.

Keywords chemiluminescence, electron paramagnetic resonance, phenothiazine, spin trapping.

\section{Introduction}

Acepromazine (ACP) is a phenothiazine that is used for sedation and as part of general anesthesia in animals. It exerts sedative, anti-arrhythmic and vasodilatory properties, which are considered to explain the protective effect of this drug against 
perioperative mortality during general anaesthesia in horses (Johnston et al. 2002). In particular, the ACP seems to counterbalance the a2-agonistinduced reduction in cardiac output and increase in pulmonary vasoconstriction, leading to improved arterial oxygenation when both drugs are administered concomitantly during total intravenous anaesthesia in normovolemic horses (Marntell et al. 2005). In addition, ACP is used for the treatment of horses with acute laminitis (Slater et al. 1995). Its vasodilatory effect can explain some of its beneficial therapeutic properties (Ingle-Fehr \& Baxter 1999), but other pharmacological properties, such antioxidant and anti-inflammatory effects may also contribute to the therapeutic result. Phenothiazines and their derivatives have been investigated for their interesting pharmacological activity. Some phenothiazines like e.g. thioridazine, trifluoperazine and chlorpromazine have been described to exhibit immunomodulating activities, depending on the drug, the dose and the leucocyte model used (Elferink 1979; Richter 1990; Blackwood \& Hessler 1996). Phenothiazines inhibit the production of reactive oxygen species (ROS) by phorbol myristate acetate (PMA)-stimulated human neutrophils (Szuster-Ciesielska et al. 2004). In horses, previous studies on isolated equine neutrophils have demonstrated, by luminol-dependent chemiluminescence, that ACP is able to decrease the histamine-, lipopolysaccharide- and PMA-induced chemiluminescent activity (Serteyn et al. 1999). Interestingly, Péters et al. (2009) showed that after an in vivo administration of promethazine or ACP to horses, the antioxidant effect of these drugs still persist in isolated and washed neutrophils. These findings could be explained by the capacity of ACP to interfere with intracellular activation pathways. However, those results have been obtained with luminol as probe that is readily oxidized and can react with various oxidant agents (Münzel et al. 2002). These authors also reported that lucigenin is a more accurate probe to evidence the production of superoxide anion $\left(\mathrm{O}_{2}^{--}\right)$. This probe was recently used by Franck et al. (2009) to evidence the production of $\mathrm{O}_{2}^{--}$by stimulated equine neutrophils. But $\mathrm{O}_{2}^{--}$, the first species produced either at cellular level from NADPH oxidase or at intracellular level by mitochondria, can undergo secondary reactions responsible of the formation of other ROS such as hydrogen peroxide $\left(\mathrm{H}_{2} \mathrm{O}_{2}\right)$ and hydroxyl radical $\left({ }^{\bullet} \mathrm{OH}\right)$. Additionally, $\mathrm{O}_{2}^{--}$could also react with nitric oxide $\left(\mathrm{NO}^{\bullet}\right)$ derived from nitric oxide synthase leading to the formation of a powerful nitrogen species, peroxynitrite. To detect reactive nitrogen and oxygen species (RNOS), various methodologies have been reported, all with advantages and disadvantages, but the unique analytical technique that allows accurate measurement of free radicals is electron paramagnetic resonance (EPR). This technique is similar to nuclear magnetic resonance which deals with nuclear spin but takes into account unpaired or electronic spins. This involves absorption of microwave energy by paramagnetic species in the presence of an external magnetic field resulting in the transition of spin states. In biological conditions, the detection of free radicals directly by EPR is very difficult because of their short lifetime. To overcome this problem spin trapping technique is used. Spin trapping allows the detection of transient radicals, i.e. $\mathrm{OH}^{\bullet}, \mathrm{O}_{2}^{-}$, $\mathrm{ROO}^{\circ}$ or $\mathrm{NO}^{*}$. Depending on the nature of free radicals and their cellular localization, the researcher will choose a spin trap agent that will be more specific for radical trapping. Further cellular toxicity of trapping agents such as 5,5-dimethyl-pyrolline- $\mathrm{N}$-oxide (DMPO) or $\alpha$-phenyl-tert-butylnitrone is low, hence making them suitable for application in biological systems. However, since few laboratories have an EPR apparatus, other techniques such as chemiluminescence and fluorescence are employed. Depending on the probes used, those latter techniques can monitor either activated species or global ROS in biological systems.

The aim of the present study is to better understand the mechanism of action of ACP towards ROS production by PMA-activated equine neutrophils. To achieve this goal, three different techniques have been used: 1) lucigenin-enhanced chemiluminescence for targeting the superoxide anion generation, 2) gas chromatography for ethylene measurement derived from ROS-induced $\alpha$-keto- $\gamma$-methylthiobutyric oxidation and 3) electron paramagnetic resonance-spin trapping to evidence accurately the free radical production.

\section{Materials and methods}

\section{Reagents}

Analytical grade $\mathrm{Na}$ and $\mathrm{K}$ salts, ethanol, dimethylsulfoxide (DMSO), hydrogen peroxide $(30 \% \mathrm{w} / \mathrm{v})$ and Tween 20 were from Merck (Belgium). Bovine serum albumin, lucigenin (bis- $\mathrm{N}$-methylacridinium nitrate), percoll, phorbol 12-myristate 13-acetate 
(PMA), $\alpha$-keto- $\gamma$-methylthiobutyric acid (KMB) were purchased from Sigma-Aldrich (Belgium). Microtitration plates (Cliniplate EB, Belgium) and White Combiplate 8 were from Fisher Scientific (Belgium). Amplex red substrate was purchased from Invitrogen (Belgium). Acepromazine maleate (1-[10-[3(dimethylamino)propyl]phenothiazin-2-yl]ethanone maleate salt) was purchased from Sigma (Germany). 5,5-Dimethyl-pyrolline- $N$-oxide (DMPO) was from Alexis Biochemicals (Switzerland). Analytical grade phosphate salts were from Merck. All chemicals were of analytical grade.

\section{Isolation of equine neutrophils}

Neutrophils were isolated from blood drawn from the jugular vein of healthy horses into ethylenediamine-tetra-acetic acid containing tubes $(1.6 \mathrm{mg}$ $\mathrm{mL}^{-1}$ blood). The horses were kept and fed under standardized conditions (Faculty of Veterinary Medicine, University of Liège, Belgium). They were clinically healthy and had no medical treatment. Each batch of neutrophils was obtained from $60 \mathrm{~mL}$ blood drawn from one horse, the cells were used immediately after isolation; the experiment was completed within 4 hours. Each experiment was repeated 2 to 4 times with different cell batches from different horses. The neutrophils were isolated at room temperature $\left(18-22^{\circ} \mathrm{C}\right)$ by centrifugation $\left(400 \mathrm{~g}, 30\right.$ minutes, $\left.20^{\circ} \mathrm{C}\right)$ on a discontinuous percoll density gradient according to the method of Pycock et al. (1987). The polymorphonuclear fraction was gently collected and washed in two volumes of physiological saline solution. The cell pellets were suspended in $20 \mathrm{~mm}$ phosphate buffer saline (PBS) at $\mathrm{pH} 7.4$ containing $137 \mathrm{~mm} \mathrm{NaCl}$ and $2.7 \mathrm{~mm} \mathrm{KCl}$. The cell preparation contained $\geq 90 \%$ neutrophils with a viability of $95 \%$ as measured by the trypan blue exclusion test.

\section{Measurement of ROS production by stimulated neutrophils}

\section{By chemiluminescence (CL)}

The ROS production by activated neutrophils was measured by CL according to the method of Benbarek et al. (1996) with minor modifications. In our conditions, the assay was performed on microtitre plates and CL was read with a Fluoroscan Ascent FL (Fisher Scientific, Belgium). Neutrophil suspensions were distributed in the wells of a 96 well microtitre plate (Fisher Scientific) in order to obtain $10^{6}$ neutrophils per well. The cells were incubated for 10 minutes at $37^{\circ} \mathrm{C}$ with ACP at the final concentration of $10^{-4}, 10^{-5}$ or $10^{-6} \mathrm{M}$. After the incubation, $25 \mu \mathrm{L} \mathrm{CaCl}_{2}(7.5 \mu \mathrm{M}), 2 \mu \mathrm{L}$ lucigenin $(5 \mu \mathrm{M})$ and $10 \mu \mathrm{L}$ PMA $\left(1.6 \times 10^{-5} \mathrm{M}\right)$ were added. The final volume assay with the cells, ACP and reagents was $200 \mu \mathrm{L}$. Just after PMA addition, the CL response of neutrophils was monitored for 30 minutes at $37{ }^{\circ} \mathrm{C}$ and expressed as the integral value of the total $\mathrm{CL}$ emission obtained in millivolts per minute $\left(\mathrm{mV}\right.$ minute $\left.{ }^{-1}\right)$. Control assays were performed with unstimulated and PMA-stimulated neutrophils where the ACP solution was replaced by an equivalent volume of $20 \mathrm{~mm}$ PBS $\mathrm{pH} 7.4$ (vehicle of ACP). The PBS control with PMAstimulated neutrophils was taken as $100 \%$ of CL response.

\section{By ethylene production from KMB oxidation}

If neutrophils are stimulated with PMA in the presence of $\alpha$-keto- $\gamma$-methylthiobutyric acid (KMB) they release ROS in the extracellular medium. The ROS react with KMB, which decomposes into ethylene, measured by a gas chromatography technique. This technique has been reported in detail in previous papers (Mouithys-Mickalad et al. 2001; Deby-Dupont et al. 2005; Kohnen et al. 2007). Isolated equine neutrophils $\left(10^{6}\right.$ cells $\left.\mathrm{mL}^{-1}\right)$ were suspended in PBS with glucose (1.5 $\left.\mathrm{mg} \mathrm{mL}^{-1} \mathrm{PBS}\right)$. One $\mathrm{mL}$ of the neutrophil suspension was preincubated for 10 minutes at room temperature with $\operatorname{ACP}\left(10^{-4}, 10^{-5}\right.$, and $\left.10^{-6} \mathrm{M}\right)$ and the vehicle solution of ACP (20 mm PBS, pH 7.4) in a $10 \mathrm{~mL}$ vial. Then, KMB and PMA were added at final concentrations of $10^{-3} \mathrm{M}$ and $8 \times 10^{-7} \mathrm{M}$, respectively. Immediately afterwards, the vials were sealed and incubated for 1 hour at $37^{\circ} \mathrm{C}$. The level of $\mathrm{KMB}$ oxidation was estimated by measuring the ethylene amount released into the gaseous phase. Ethylene was quantified by gas chromatography on a Porapak T column ( 1 m length; ID 1/8 inch; supplied by Supelco, Belgium) at $80{ }^{\circ} \mathrm{C}$ using nitrogen as vector gas $\left(40 \mathrm{~mL} \mathrm{minute}{ }^{-1}\right)$, with flame ionization detector at $120{ }^{\circ} \mathrm{C}$ and results were obtained in $\mathrm{mV}$ minute $^{-1}$. The KMB oxidation related to PMNROS production was expressed as the integral value of the ethylene peak area. The gas chromatography column was standardized with pure ethylene $\left(\mathrm{C}_{2} \mathrm{H}_{4}\right.$ 25 quality, Air Liquide, Belgium). The gas samples $(0.5 \mathrm{~mL})$ were obtained by puncture through the 
sealed membrane with a $1 \mathrm{~mL}$ Hamilton gas syringe A-2 (Vici Precision Sampling Inc., LA, USA).

\section{EPR studies}

All electron paramagnetic resonance (EPR) spectra were recorded at room temperature in a quartz flat cell on a Bruker ESP 300E spectrometer equipped with a simple $\mathrm{TM}_{110}$ cavity (Bruker, Germany), operating at X-band frequency $(9.8 \mathrm{GHz})$ and $20 \mathrm{~mW}$ of microwave power. The instrumental settings were the following: $100 \mathrm{KHz}$ modulation frequency, $1.012 \mathrm{G}$ modulation amplitude, $3480 \mathrm{G}$ magnetic field centre, and receiver gain was 20,000. The sweep width was $100 \mathrm{G}$ and the total number of scans was 4 . The hyperfine splitting constants were measured from the experimental spectra by means of a Bruker Win-Sinfonia program running under Microsoft Windows.

To study the ability of ACP to interact with free radical species, two additional experiments were designed from equine neutrophils in parallel to CL and gas chromatography assays. In the first experiment, the EPR analysis was performed with PMA-stimulated cells $\left(6 \times 10^{6}\right.$ cells $\left.\mathrm{mL}^{-1}\right)$ in the presence of ACP $\left(10^{-6}, 10^{-5}\right.$ or $\left.10^{-4} \mathrm{M}\right)$ directly added in the reaction mixture (cell suspension). In the second experiment, increasing concentrations of ACP $\left(10^{-6}, 10^{-5}\right.$ or $\left.10^{-4} \mathrm{M}\right)$ were pre-incubated with neutrophils $\left(6 \times 10^{6}\right.$ cells $\left.\mathrm{mL}^{-1}\right)$ for $30 \mathrm{~min}$ utes. Afterwards, cells were centrifuged $(1000 \boldsymbol{g}$, 10 minutes) and the supernatant was discarded to eliminate the excess of ACP. Cells were re-suspended with $20 \mathrm{~mm}$ phosphate buffer $(\mathrm{pH}$ 7.4) then stimulated with $5 \times 10^{-7}$ м PMA for analysis. Results represent mean values of two independent assays (in duplicate).

\section{Data presentation and statistical analysis}

Three independent experiments were made with different blood batches and carried out in duplicate for $\mathrm{KMB}$ oxidation $(n=6)$ and in triplicate for CL measurement $(n=9)$. Within each experiment, values of CL and gas chromatography obtained in $\mathrm{mV}$ minute $^{-1}$ were expressed as integral values of total CL emission and ethylene peak respectively. As the PMN stimulation varied with neutrophil batches, we transformed for each experiment, the integral values in relative percentage by taking as $100 \%$ the mean value obtained with PMA stimulated (ST) cells without ACP (control 100\%). All the data transformed in percentage were used to calculate the mean \pm standard deviation (SD). An ANOVA with a post hoc test (Bonferroni's) was performed with the GraphPad Instat 3.05 (GraphPad Software, CA, USA). A $p$-value $<0.05$ was considered significant.

\section{Results}

Effects of ACP on the ROS production by stimulated neutrophils: CL response and KMB oxidation

The stimulation of neutrophils with PMA increased significantly the CL production (4.4 times) in comparison to unstimulated cells (Fig. 1). In the case of stimulated and unstimulated controls ACP was replaced by an equivalent volume of $20 \mathrm{~mm}$ PBS pH 7.4 (vehicle solution of ACP). When ACP was incubated with stimulated neutrophils, a concentration-dependent decrease of the CL was observed. The CL production was significantly decreased by $55 \pm 12 \%$ and $95 \pm 4 \%$ at $10^{-5}$ and $10^{-4} \mathrm{M} \mathrm{ACP}$, respectively (Fig. 1). The percentages of inhibition were calculated by taking as $100 \%$ the PMA stimulated neutrophils control without ACP.

Similar results were observed in the model of KMB oxidation monitored by gas chromatography. The stimulation of neutrophils with PMA increased significantly the KMB oxidation (4.1 times) in comparison to unstimulated cells (Fig. 2). When ACP was incubated with stimulated neutrophils, a dose-dependent decrease of the KMB oxidation was observed with significant decrease by $52 \pm 23 \%$ and $85 \pm 4 \%$ at $10^{-5}$ and $10^{-4} \mathrm{M} \mathrm{ACP}$, respectively (Fig. 2).

At the low concentration of $10^{-6} \mathrm{M}$, ACP the effect on the ROS produced within neutrophils was not significantly different than the control (10 and $22 \%$ inhibitory effect for CL and KMB oxidation, respectively). Independently of the technique used, the inhibitory response is quite similar and significantly $(p<0.05)$ inhibited at $10^{-4}$ and $10^{-5} \mathrm{M}$.

\section{Effect of various concentrations of ACP $\left(10^{-6}\right.$ to $\left.10^{-4} \mathrm{M}\right)$ on the free radicals produced by PMA-activated equine neutrophils: EPR-spin trapping investigation}

The EPR-spin trapping experiments with activated equine neutrophils were carried out using 5,5dimethyl-pyrroline- $\mathrm{N}$-oxide (DMPO, $100 \mathrm{~mm}$ final concentration), in the presence and absence of ACP. 


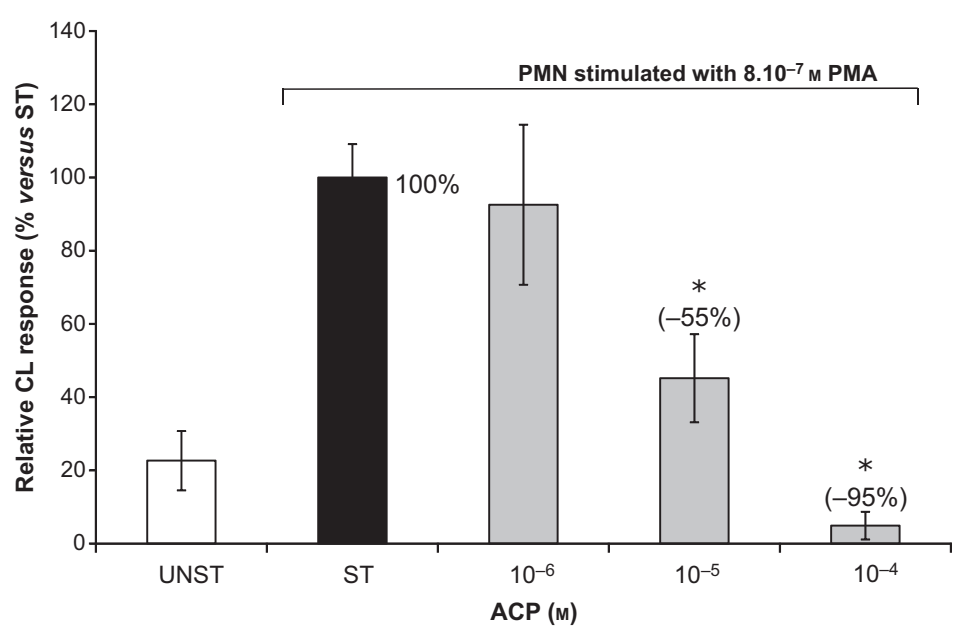

Figure 1 Effect of acepromazine (ACP) on reactive oxygen species production of phorbol myristate acetate (PMA)stimulated equine neutrophils measured by the lucigenin-enhanced chemiluminscence (CL). Results are expressed in relative values (\%) in reference to phorbol myristate acetate (PMA) stimulated cells (ST) taken as 100\% (dark column). Data are means \pm SD of at least three independent experiments carried out in triplicate $(n=9)$. *Significantly different from stimulated cells $\left({ }^{*} p<0.05\right)$ as analysed by ANova with a post hoc test (Bonferroni's). The percentage of inhibition is indicated in brackets on the top of the column. UNST = unstimulated cells in the diluent of PMA.

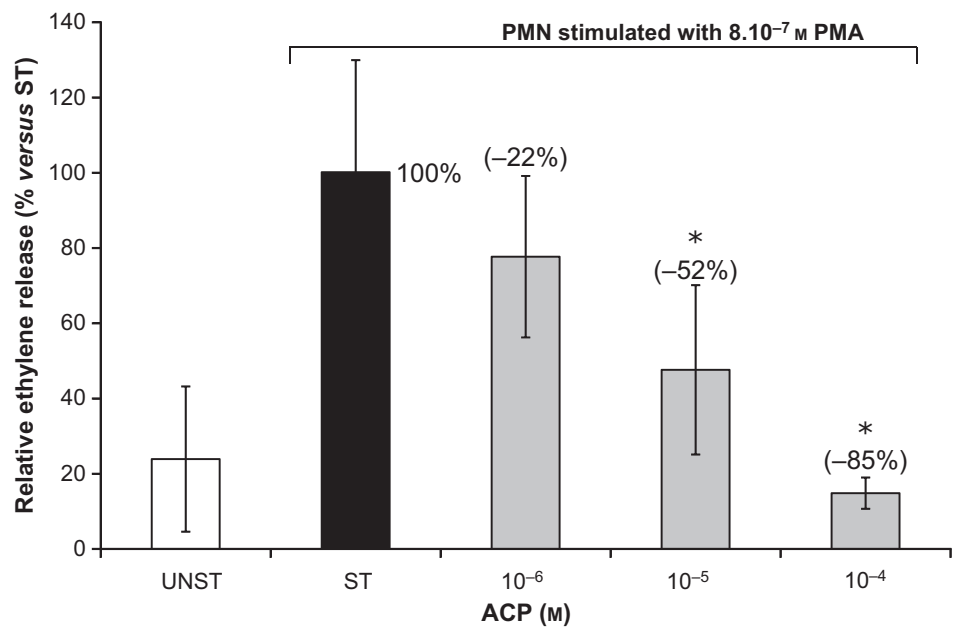

Figure 2 Effect of acepromazine (ACP) on reactive oxygen species production of phorbol myristate acetate (PMA)stimulated equine neutrophils measured by $\alpha$-keto- $\gamma$-methylthiobutyric acid oxidation. Results are expressed in relative values (\%) in reference to phorbol myristate acetate (PMA) stimulated cells (ST) taken as $100 \%$ (dark column). Data are means \pm SD of at least three independent experiments carried out in triplicate $(n=6)$. *Significantly different from stimulated cells $\left({ }^{*} p<0.05\right)$ as analysed by ANOva with a post hoc test (Bonferroni's). The percentage of inhibition is indicated between brackets. UNST = unstimulated cells in the diluent of PMA.

In the absence of ACP, the activation of equine neutrophils with $5 \times 10^{-7}$ м PMA resulted in the appearance of a high EPR spectrum (Fig. 3, spectrum a) compared to the unstimulated cells that showed a very weak EPR signal (data not shown). In contrast, when ACP was incubated with neu- trophils for less than 10 minutes, a concentrationdependent decrease of the EPR signal intensity was observed (Fig. 4). The four-line EPR spectrum was characteristic of both DMPO-OOH and DMPO-OH adducts, resulting from the trapping of superoxide anion by the spin trap agent DMPO (Mouithys- 


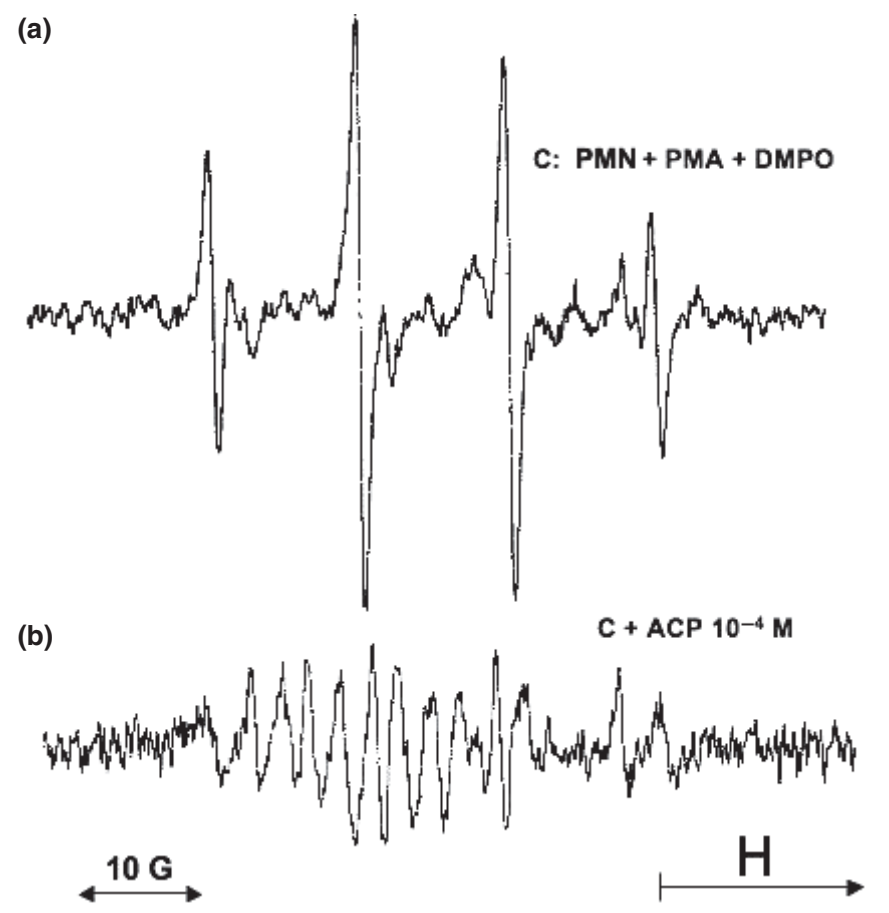

Figure 3 Electron magnetic resonance (EPR) spectra of 5,5-dimethyl-pyrolline-N-oxide (DMPO)-OOH and DMPO-OH spin adducts (a) and of acepromazyl cation radical (b) obtained when acepromazine $\left(10^{-4} \mathrm{M}\right)$, in the absence of DMPO, was exposed to free radicals during respiratory burst.

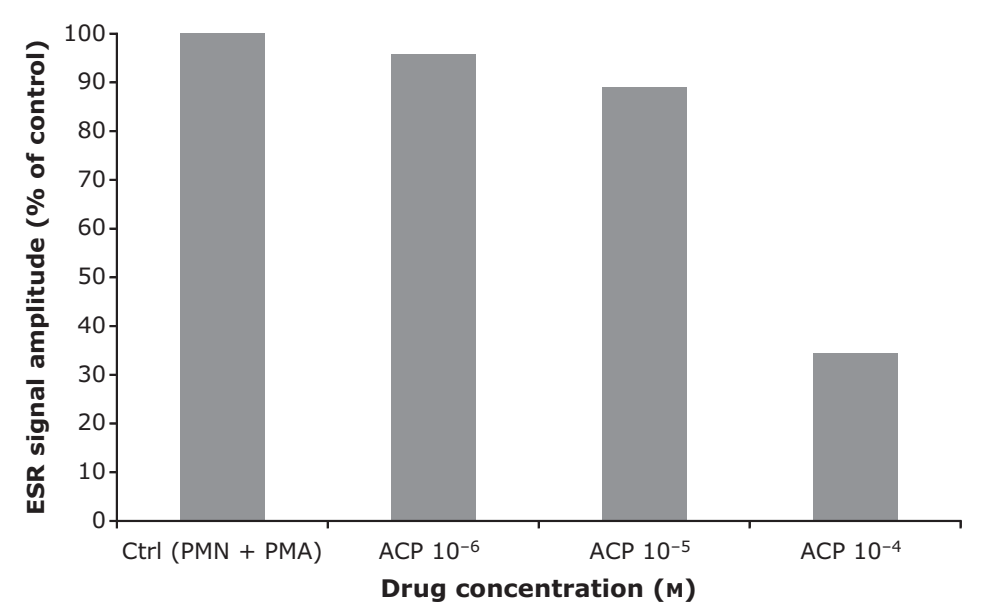

Figure 4 Effect of increasing concentrations of acepromazine (ACP) $\left(10^{-6}, 10^{-5}\right.$ and $\left.10^{-4} \mathrm{M}\right)$ on the electron magnetic resonance (EPR) signal intensity of the 5,5-dimethyl-pyrolline-N-oxide (DMPO)-OOH and/or DMPO-OH adducts. Reactive oxygen species were produced from phorbol myristate acetate (PMA)-stimulated equine neutrophils (PMN) in the presence of different concentrations of ACP and 100 mм DMPO in 20 mm phosphate buffer (pH 7.4).

Mickalad et al. 1997). The hyperfine coupling constants were: 1 ) a $(\mathrm{N})=14.5 \mathrm{G},\left(\mathrm{a}_{\mathrm{H}}\right)^{\alpha}=11.3 \mathrm{G}$, $\left(\mathrm{a}_{\mathrm{H}}\right)^{\beta}=1.3 \mathrm{G}$ for DMPO-OOH and 2) a $(\mathrm{N})=\mathrm{a}$ $(\mathrm{H})=14.9 \mathrm{G}$ for DMPO-OH (Fig. 3, spectrum a).
Interestingly, when a high concentration of ACP $\left(10^{-4} \mathrm{M}\right)$ was employed, a complex EPR spectrum was detected (Fig. 3, spectrum b). This multi-line EPR spectrum is obtained without the use of DMPO 


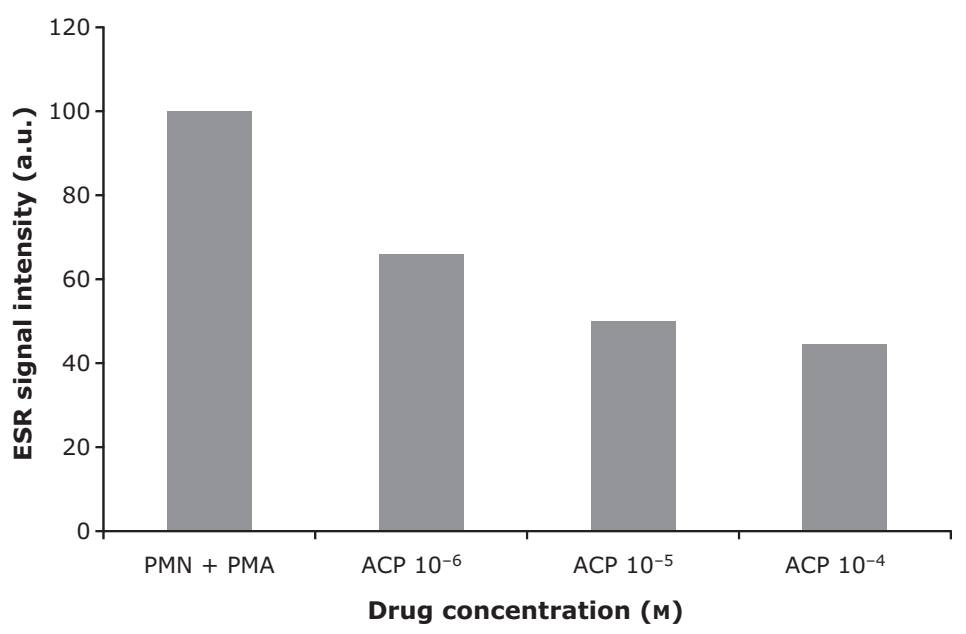

Figure 5 Effect of pre-incubation with increasing concentrations of acepromazine (ACP) $\left(10^{-6}, 10^{-5}\right.$ and $\left.10^{-4} \mathrm{M}\right)$ on the EPR signal intensity of the 5,5-dimethyl-pyrolline- $N$-oxide (DMPO)-OOH and/or DMPO-OH spin adducts. After ACP preincubation for 30 minutes, neutrophils (PMN) were washed and excess ACP discarded before stimulation with $5 \times 10^{-7} \mathrm{M}$ PMA. Reactive oxygen species were produced from phorbol myristate acetate (PMA)-stimulated equine neutrophils (PMN) in the presence of 100 mм DMPO in 20 mм phosphate buffer (pH 7.4).

as spin trap and was assigned to the formation of acepromazyl cation radical.

In parallel to this experiment, we have studied the effect of pre-incubation of ACP with neutrophils $\left(6 \times 10^{6}\right.$ cells $)$ for 30 minutes, followed by a subsequent cell washing before their stimulation with $5 \times 10^{-7}$ м PMA. We have observed a pronounced inhibitory effect on the EPR signal intensity, even after discarding the excess of ACP within the medium, compared to the control PMA stimulated neutrophils taken as $100 \%$ (Fig. 5).

\section{Discussion}

Systemic inflammatory response syndrome has been recognized as appropriate terminology to define the host response to an inflammatory process independent of its cause (Bone et al. 2009). Intensively studied in man and in animal models, it is also recognized as a clinical syndrome in horses (Eades et al. 2008). Neutrophils are believed to play the key role in the pathogenesis of the systemic inflammatory response syndrome. Their stimulation results in an increase of their oxygen consumption (respiratory burst) with a production of reactive oxygen and nitrogen species by the combined activities of NADPH oxidase and nitric oxide synthase. The superoxide anion $\left(\mathrm{O}_{2}^{-}\right)$produced by the activity of NADPH oxidase is the primary reactive oxygen species involved in the formation of secondary reactive nitrogen and oxygen species such as hydrogen peroxide $\left(\mathrm{H}_{2} \mathrm{O}_{2}\right)$, hydroxyl radical $\left(\mathrm{OH}^{*}\right)$ or peroxynitrite (Deby-Dupont et al. 1999). These reactive species are important for host clearance of pathogens, but, during an excessive inflammation, their release in the extracellular medium leads to tissue damage (Morishita et al. 1987; Deby-Dupont et al. 1999; Klebanoff 2005). Further, neutrophils discharge hydrolytic and proteolytic enzymes, like e.g. myeloperoxidase, an oxidant enzyme responsible of the formation of strong oxidant species such as $\mathrm{HOCl}$ and $\mathrm{NO}_{2}{ }^{\circ}$.

Several models can be used to stimulate neutrophils. Some models use receptor linked agents (LPS, Zymosan, TNF- $\alpha$, PGN, TLR-5) that act by indirect mechanisms via receptors related to $G$ proteins and the cytoskeleton. This leads to the stimulation of chemotaxis, exocytosis and multiple signalling pathways including the production of second messengers and the activation of protein kinase C (El-Benna et al. 2008). With these models the activation of NADPH oxidase is indirect and moderate. In our model, we used PMA which is a powerful molecule for neutrophilic stimulation. It crosses the membrane and directly stimulates the protein kinase $\mathrm{C}$ pathway leading to the assembly of NADPH oxidase subunits responsible for the enzyme activation and $\mathrm{O}_{2}^{--}$production (El-Benna et al. 2008). A therapeutic goal in inflammatory pathologies is to decrease excessive inflammation by 
modulating the oxidant response properties of the neutrophil. Various inhibitors of neutrophil activation have proven to increase survival rates in several models of sepsis and inflammation (Parson et al. 1989; Paterson et al. 1989; Schonharting \& Schade 1989; Schade 1990). Among these molecules phenothiazines are of special interest because they can inhibit the production of $\mathrm{O}_{2}^{--}$by PMAstimulated human neutrophils (Szuster-Ciesielska et al. 2004) and modulate their degranulation (Elferink 1979; Richter 1990; Blackwood \& Hessler 1995).

In previous studies, our group has shown that ACP induces interesting modulator effects on neutrophil activation. These effects are mainly studied on the capacity of ACP to neutralize ROS produced by stimulated equine neutrophils by using luminolenhanced chemiluminescence (Serteyn et al. 1999; Péters et al. 2009). Luminol is a membrane permeable dye which is readily oxidized by a variety of ROS, including $\mathrm{H}_{2} \mathrm{O}_{2}$, hydroxyl radical, hypochlorous acid, and peroxynitrite (Münzel et al. 2002), indicating a lack of specificity. In the present study, we have used lucigenin as a chemiluminescent probe. It is a reliable tool for measuring extracellular $\mathrm{O}_{2}^{--}$as it does not enter into the cells (Li et al. 1998; Caldefie-Chézet et al. 2002). Nevertheless, the specificity of lucigenin to measure ROS is controversial (Tarpey \& Fridovich 2001) since it can entertain the redox cycling within cells and induce false positive controls (Spasojevic et al. 2000). However, this inconvenience can be surmounted when lucigenin is used at low concentrations, for instance less than $50 \mu \mathrm{M}$ (Münzel et al. 2002). Lucigenin can either compete with ACP when reacting with ROS or transform into radical form (Luc+). At this step, ACP can induce a decrease of lucigenin-amplified CL followed by subsequent formation of acepromazyl radical but this radical cannot be detected by CL. Indeed, luminescent probes as well as fluorescent ones such as dichlorofluorescin diacetate are generally used to evidence RNOS but not radical species. If these techniques are very sensitive, their selectivity towards particular species is still debated (Myhre et al. 2003), but this lack of selectivity could be overcome by performing appropriate controls or by confirming results with other experimental models.

In parallel to the CL assays, the method of KMB oxidation was used to consolidate our results. The ROS produced by neutrophils induced the KMB decomposition into ethylene. This gas is then measured by gas chromatography without interferences due to colour or lack of homogeneity of the reaction medium (i.e., cell suspensions or tissue samples) (Von Kruedener et al. 1995; MouithysMickalad et al. 2001; Deby-Dupont et al. 2005). The oxidation of KMB is mainly attributed to the formation of $\mathrm{OH}$-radical type species derived from the Fenton-like reactions with $\mathrm{H}_{2} \mathrm{O}_{2}$ the first byproduct of $\mathrm{O}_{2}^{--}$(Hippeli et al. 1997). Using gas chromatography, ethylene can be quantified and the effect of ACP on stimulated equine neutrophil investigated. The inhibitory effect of ACP measured by the method of KMB oxidation was found to be similar to that measured by lucigenin-enhanced luminescence. This parallelism suggests that ACP early neutralizes $\mathrm{O}_{2}^{--}$that becomes less available for the secondary reactions leading to the formation of transient oxoferryl species or superoxide anion by-products.

In parallel to chemiluminescence and $\mathrm{KMB}$ oxidation, we have used EPR spectroscopy to monitor the interaction of ACP with free radicals generated by activated equine neutrophils. EPR spectroscopy remains the unique technique to demonstrate the formation of free radicals within the reaction mixture (Janzen 1971; Finkelstein et al. 1980; Villamena \& Zweier 2004). In a first experiment, the EPR signal was followed from stimulated neutrophils in the presence of ACP. The four-line EPR spectrum observed was characteristic of both DMPO-OOH and DMPO-OH adducts, resulting from the trapping of $\mathrm{O}_{2}^{--}$with the spin trap agent DMPO (Mouithys-Mickalad et al. 1997). Since ACP was added just before the experiment, the decrease of the EPR spectrum in relation with the increase of ACP concentration showed the role of ACP as a scavenger of free radicals derived from $\mathrm{O}_{2}^{--}$production as already suggested by lucigenin-enhanced chemiluminescence and KMB oxidation. Interestingly, by performing the experiment with ACP in the medium without DMPO, at a concentration of $10^{-4} \mathrm{M}$, a multi-line spectrum is detected by EPR and assigned to acepromazyl cation radical. This transient species has a short half-life and after few minutes, the corresponding EPR spectrum disappears; that is reminiscent of the formation of the cation radical from phenothiazine derivatives as previously described for chlorpromazine in vitro systems (Chignell et al. 1985).

In a second EPR experiment, we pre-incubated cells for 30 minutes with ACP then eliminated its excess before neutrophil stimulation and ROS 
detection. After the washing step, ACP still showed an inhibitory effect on free radicals produced. This decrease appeared more important than previously observed when cells were just put in contact with ACP. These findings showed that ACP, after a sufficient contact time with neutrophils, interacts with their membrane or elements inside the cell. The interaction between neutrophils and ACP could lead further to the inhibition of NADPH oxidase either by hindering the assembly of its different cytosolic components or by disturbing the plasma membrane. Indeed, several studies showed a cellular action of phenothiazines. Cohen et al. (1980) suggest an effect of phenothiazines on the polarization and the fluidity of the membrane, leading to disturbed activity of NADPH oxidase or to a loss of rigidity of previously formed complexes. Yde et al. (2009) demonstrated that chlorpromazine interacts strongly with lipid bilayers leading to increased permeability of membranes. Other authors (Jones et al. 1982; Hadjimitova et al. 2003) also report that phenothiazines could interfere with the calcium-dependent stimulation of NADPH oxidase.

Curiously, in the EPR experiment where the ACP was eliminated before the stimulation of neutrophils, a multi-line spectrum assigned to acepromazyl cation radical was not observed while this spectrum was observed when neutrophils were in the presence of $10^{-4} \mathrm{M}$ ACP. These observations suggest that ACP outside the cells acts as a free radical scavenger becoming a cation radical detected only by EPR at the highest concentration. These mechanisms are also described by the formation of the tocopheryl or ascorbyl radicals (Sies \& Stahl 1995). These observations may be related to myeloperoxidase activity. Eghbal et al. (2004) showed that phenothiazines can interfere with the redox cycling of peroxidase in in vitro models, leading to the formation of acepromazyl cation radical at physiological pH. Gutiérrez-Correa \& Stoppani (2002) reported the formation of phenothiazine (PHE) cation radicals by myeloperoxidase. Several investigators suggest that PHE radicals are important intermediates in the metabolism of the drug and might be the active pharmacological entity while others authors suggest that PHE radical metabolites could contribute to oxidative stress at a neutral $\mathrm{pH}$ resulting in cytotoxicity (Eghbal et al. 2004).

This ex vivo study tested three different doses of ACP. Detailed knowledge on the pharmacokinetic behaviour of ACP in horses is lacking, however, it has been estimated that a single intravenous injection of $0.1 \mathrm{mg} \mathrm{kg}^{-1}$ bodyweight of ACP would result in a plasma concentration of $4.6 \times 10^{-6} \mathrm{M}$ in horses (Péters et al. 2009). This corresponds to a concentration slightly higher than the lower concentrations tested in the present study.

The modulating effects of ACP on ROS generation by PMA stimulated equine neutrophils are probably explained both by an intracellular or membrane effect and by an extracellular scavenger effect. Further studies are needed to explore the specific effects of phenothiazines on the activities of the neutrophilic enzymes. By inhibiting the oxidant action of neutrophils, ACP may find a place in the treatment of equine diseases with neutrophil-dominated inflammation, like e.g. systemic inflammatory response syndrome or laminitis.

\section{Acknowledgements}

The authors would like to thank Ms. Jennifer Romainville and Ms. Ariane Niesten for their excellent technical support.

\section{References}

Benbarek H, Deby-Dupont G, Deby C et al. (1996) Experimental model for the study by chemiluminescence of the activation of isolated equine leucocytes. Res Vet Sci 61, 59-64.

Blackwood RA, Hessler RJ (1995) Effect of calcium on phenothiazine inhibition of neutrophil degranulation. J Leukoc Biol 58, 114-118.

Bone RC, Balk RA, Cerra FB et al. (2009) ACCP/SCCM Consensus Conference Committee. Definitions for sepsis and organ failure and guidelines for the use of innovative therapies in sepsis. Chest 136, e28.

Caldefie-Chézet F, Walrand S, Moinard C et al. (2002) Is the neutrophil reactive oxygen species production measured by luminol and lucigenin chemiluminescence intra or extracellular? Comparison with DCFH-DA flow cytometry and cytochrome c reduction. Clin Chim Acta 319, 9-17.

Chignell CF, Motten A, Buttner GR (1985) Photoinduced free radicals from chlorpromazine and related phenothiazine: related photosensitization. Environ Health Perspect 64, 103-110.

Cohen HJ, Chovaniec ME, Ellis SE (1980) Chlorpromazine inhibition of granulocyte superoxide production. Blood 56, 23-29.

Deby-Dupont G, Deby C, Lamy M (1999) Neutrophil myeloperoxidase revisited: it's role in health and disease. Intensivmedizin und Norfallmedizin 36, 500-501.

Deby-Dupont G, Mouithys-Mickalad A, Serteyn D et al. (2005) Resveratrol and curcumin reduce the respiratory 
burst of Chlamydia-primed THP-1 cells. Biochem Biophys Res Commun 333, 21-27.

Eades SC, Fugler LA, Riggs L (2008) Controlling the equine neutrophil: a generator of devastating tissue damage during equine inflammatory disease. Vet J 178, 3-4.

Eghbal MA, Tafazoli S, Pennefather P et al. (2004) Peroxidase catalysed formation of cytotoxic prooxidant phenothiazine free radicals at physiological $\mathrm{pH}$. Chem Biol Interact 151, 43-51.

El-Benna J, Dang PM, Gougerot-Pocidalo MA (2008) Priming of the neutrophil NADPH oxidase activation: role of p47phox phosphorylation and NOX2 mobilization to the plasma membrane. Semin Immunopathol 30, 279-289.

Elferink JG (1979) Chlorpromazine inhibits phagocytosis and exocytosis in rabbit polymorphonuclear leukocytes. Biochem Pharmacol 28, 965-968.

Finkelstein E, Rosen GM, Raukman EJ (1980) Spin trapping of superoxide and hydroxyl radical: practical aspects. Arch Biochem Biophys 200, 1-16.

Franck T, Kohnen S, de la Rebière G et al. (2009) Activation of equine neutrophils by phorbol myristate acetate or $\mathrm{N}$-formyl-methionyl-leucyl-phenylalanine induces a different response in reactive oxygen species production and release of active myeloperoxidase. Vet Immunol Immunopathol 130, 243-250.

Gutiérrez-Correa J, Stoppani AO (2002) Myeloperoxidasegenerated phenothiazine cation radicals inactivate Trypanosoma cruzi dihydrolipoamide dehydrogenase. Rev Argent Microbiol 34, 83-94.

Hadjimitova V, Bakalova R, Traykov T et al. (2003) Effect of phenothiazines on protein kinase C- and calciumdependent activation of peritoneal macrophages. Cell Biol Toxicol 19, 3-12.

Hippeli S, Rohnert U, Koske D et al. (1997) OH-radical-type reactive oxygen species derived from superoxide and nitric oxide: a sensitive method for their determination and differentiation. Z Naturforsch C 52, 564-570.

Ingle-Fehr JE, Baxter GM (1999) The effect of oral isoxsuprine and pentoxifylline on digital and laminar blood flow in healthy horses. Vet Surg 28, 154-160.

Janzen EG (1971) Spin trapping. Acc Chem Res 4, 31-40.

Johnston GM, Eastment JK, Wood JN et al. (2002) The confidential enquiry into perioperative equine fatalities (CEPEF): mortality results of phases 1 and 2 . Vet Anaesth Analg 29, 159-170.

Jones HP, Ghai G, Petrone WF et al. (1982) Calmodulin dependent stimulation of the NADPH oxidase of human neutrophils. Biochim Biophys Acta 714, 152-156.

Klebanoff SJ (2005) Myeloperoxidase: friend and foe. J Leukoc Biol 77, 598-625.

Kohnen S, Franck T, Van Antwerpen P et al. (2007) Resveratrol inhibits the activity of equine neutrophil myeloperoxidase by a direct interaction with the enzyme. J Agric Food Chem 55, 8080-8087.

Li Y, Zhu H, Kuppusamy P et al. (1998) Validation of lucigenin (bis-N-methylacridinium) as a chemilumigenic probe for detecting superoxide anion radical production by enzymatic and cellular systems. J Biol Chem 273, 2015-2023.

Marntell S, Nyman G, Funkquist P et al. (2005) Effects of acepromazine on pulmonary gas exchange and circulation during sedation and dissociative anaesthesia in horses. Vet Anaesth Analg 32, 83-93.

Morishita K, Tsuchiya M, Asano S et al. (1987) Chromosomal gene structure of human myeloperoxidase and regulation of its expression by granulocyte colonystimulating factor. J Biol Chem 262, 15208-15213.

Mouithys-Mickalad A, Deby-Dupont G, Hoebeke M et al. (1997) Effects of sphingosine and sphingosine analogues on the free radical production by stimulated neutrophils: ESR and chemiluminescence studies. Mediators Inflamm 6, 327-333.

Mouithys-Mickalad A, Kauffmann JM, Petit C et al. (2001) Electrooxidation potential as a tool in the early screening for new safer clozapine-like analogues. J Med Chem 44, 769-776.

Münzel T, Afanas'ev IB, Kleschyov AL et al. (2002) Detection of superoxide in vascular tissue. Arterioscler Thromb Vasc Biol 22, 1761-1768.

Myhre O, Andersen JM, Aarnes H et al. (2003) Evaluation of the probes $2^{\prime}, 7^{\prime}$-dichlorofluorescin diacetate, luminol, and lucigenin as indicators of reactive species formation. Biochem Pharmacol 65, 1575-1582.

Parson PE, Warthen CS, Moore EE et al. (1989) The association of circulating endotoxin with the development of the adult respiratory distress syndrome. Am Rev Respir Dis 140, 294-300.

Paterson IS, Klausner JM, Goldman G (1989) Thromboxane mediates the ischemia-induced neutrophil oxidative burst. Surgery 106, 224-226.

Péters F, Franck T, Pequito M et al. (2009) In vivo administration of acepromazine or promethazine to horse decreases the reactive oxygen species production response of subsequently isolated neutrophils to stimulation with phorbol myristate acetate. J Vet Pharmacol Ther 32, 541-547.

Pycock JF, Allen WE, Morris TH (1987) Rapid, single-step isolation of equine neutrophils on a discontinuous Percoll density gradient. Res Vet Sci 42, 411-412.

Richter J (1990) Lymphotoxin induces secretion of granule proteins from adherent neutrophils: possible role of intracellular free calcium. J Leukoc Biol 47, 506-513.

Schade UF (1990) Pentoxifyllin increases survival in murine endotoxin shock and decreases formation of tumor necrosis factor. Circ Shock 31, 171-172.

Schonharting MM, Schade UF (1989) The effect of pentoxifyllin in septic shock-New pharmacologic aspects of an established drug. J Med 20, 97-99.

Serteyn D, Benbarek H, Deby-Dupont G et al. (1999) Effects of acepromazine on equine polymorphonuclear neutrophil activation: a chemiluminescence study. Vet J $157,332-335$. 
Sies H, Stahl W (1995) Vitamin E and C, B-Carotene and other carotenoids as antioxidants. Am J Clin Nutr 62, 1315-1321.

Slater MR, Hood DM, Carter GK (1995) Descriptive epidemiological study of equine laminitis. Equine Vet J 27, 364-367.

Spasojevic I, Batinic-Haberle I, Fridovich I (2000) Nitrosylation of manganese(II) tetrakis(N-ethylpyridinium-2yl)porphyrin: a simple and sensitive spectrophotometric assay for nitric oxide. Nitric Oxide 4, 526-533.

Szuster-Ciesielska A, Slotwinska M, Stachura A et al. (2004) Neuroleptics modulate cytokine and reactive oxygen species production in blood leukocytes of healthy volunteers. Arch Immunol Ther Exp 52, 59-67.

Tarpey MM, Fridovich I (2001) Methods of detection of vascular reactive species: nitric oxide, superoxide, hydrogen peroxide, and peroxynitrite. Circ Res 89, 224236.

Villamena FA, Zweier JL (2004) Detection of reactive oxygen and nitrogen species by EPR spin trapping. Antioxid Redox Signal 6, 619-629.

Von Kruedener S, Schempp H, Elstner EF (1995) Gas chromatographic differentiation between myeloperoxidase activity and Fenton-type oxidants. Free Radic Biol Med 19, 141-146.

Yde CW, Clausen MP, Bennetzen MV et al. (2009) The antipsychotic drug chlorpromazine enhances the cytotoxic effect of tamoxifen in tamoxifen-sensitive and tamoxifen-resistant human breast cancer cells. Anticancer Drugs 20, 723-735.

Received 19 February 2010; accepted 4 May 2010. 